\title{
Designing a Serious Game as a Diagnostic Tool
}

\author{
Pongpanote Gongsook ${ }^{1,3(\bowtie)}$, Janneke Peijnenborgh ${ }^{2}$, \\ Erik van der Spek ${ }^{1}$, Jun $\mathrm{Hu}^{1}$, Francesco Bellotti ${ }^{3}$, Riccardo Berta ${ }^{3}$, \\ Alessandro de Gloria ${ }^{3}$, Francesco Curatelli ${ }^{3}$, Chiara Martinengo ${ }^{4}$, \\ Matthias Rauterberg ${ }^{1}$, and Jos Hendriksen ${ }^{2}$ \\ ${ }^{1}$ Department of Industrial Design, Eindhoven University of Technology, \\ 5600 Eindhoven, MB, The Netherlands \\ \{p.gongsook, e.d.v.d.spek, j.hu,G.W.M. Rauterberg\}@tue.nl \\ 2 Kempenhaeghe, Center for Neurological Learning Disabilities, \\ 5591 Heeze, VE, The Netherlands \\ $\{$ PeijnenborghJ, HendriksenJ $\} @ k e m p e n h a e g h e . n l$ \\ ${ }^{3}$ ELIOS Lab - DITEN, University of Genova, \\ Via Opera Pia 11/a, 16145 Genova, Italy \\ \{franz, berta, adg\}@elios.unige.it, Curatelli@unige.it \\ ${ }^{4}$ DIMA - University of Genova, Via Dodecaneso, 35, 16145 Genova, Italy \\ martinen@dima.unige.it
}

\begin{abstract}
Serious games offer the potential to not only entertain and educate, but can also operate as a diagnostic tool. While designing a game with the goal of a diagnostic tool, we faced many challenges. In this paper, we share our experiences in dealing with these challenges in the iterations of designing, implementing, and evaluating such a tool.
\end{abstract}

Keywords: Serious game $\cdot$ Diagnostic tool $\cdot$ Game design

\section{Introduction}

Computer games offer players rich actions, immediate rewards, challenge, and appealing stories, which seem to be things we hardly get from the everyday life [1]. Next to entertainment however, games can also afford a wide variety of other applications (so-called serious games), such as learning, physical exercise, advertisement and attitude change [2]. In this paper, we describe the development of another type of serious game, namely a game that functions as a diagnostic tool. A problem with clinical assessments is that the patient is often aware of being assessed, leading to nonspecific effects such as subject-expectancy or Hawthorne effects [3]. Conversely, games offer immersion to such an extent that players forget their surroundings [4], as well as the possibility for stealth assessment [5]. Using a game could therefore improve the ecological validity of a diagnosis.

Creating a game needs more than having an individual passion. It requires collaboration of people from different disciplines working as a team, which is a common practice that most of the game companies adhere to nowadays [6]. Therefore, in addition to individual passion, effective team communication and synchronization are 
needed. In this paper, we would like to illustrate the steps taken and share our experience in developing a game as a diagnostic tool.

\section{Development Process}

The diagnostic tool we are developing strives to collect data, and thereby enhance a psychological diagnosis. Example computer games designed for a similar purpose are IntegNeuro, and Groundskeeper [7,8]. In order to create our diagnosis game, we had the following requirements:

1. The game should be usable by children aged between 4-8 years old.

2. It should be a single player game in first person perspective.

3. The game should have a controlled linear story to ensure that every player will have the same storyline.

4. The user interaction in the game is based on mouse clicks, or finger touches on a touch screen.

5. The game should be able to record user interactions.

6. It should have more than one mini-game.

7. It should be easy to modify game parameters without the need of a technical expert, in order for the diagnostic process to be conducted by non technical experts.

Our development stages of the game were separated into three iterative phases: Design, Implementation, and Evaluation (see Fig. 1). Each phase had micro iterations in the similar manner as a spiral model $[9,10]$.

\subsection{Design Phase}

We aimed to create a game for children aged between 4-8 years old. There is no game that fits all age groups [11]. Doing research by gathering data from existing games in the market can give us a hint of which kind of game children may like. To get deeper and a more direct insight, we applied the participatory design model (PD) and a user-centred design approach (UCD) during the design phase $[12,13]$. Children had been invited to our design process. Similar to 'Child's Own Studio', 'Draw Your Toy', and 'Make with Grace', custom made soft toys were used based on the children's own drawings [14-16]. We encouraged the children to express their thoughts by drawing what they thought a character would look like with provided outlines of visual elements in the game (see Fig. 2). This method provided us with a source of ideas for designing characters for the game, increasing the likelihood that the characters we designed would be accepted by children.

The game consists of multiple mini-games, designed to retain interest of the child for a single play session of roughly $30 \mathrm{~min}$. The use of more than one mini-game additionally gives us the possibility to apply more than one diagnostic instrument; that is, one for each mini-game. Books were used to give us ideas when designing mini-games [17, 18]. However, having more than one mini-game did present us with a problem: if the player is able to choose the order of the mini-games, this could result in an incoherent storyline, which could in turn lower engagement and attenuate the 


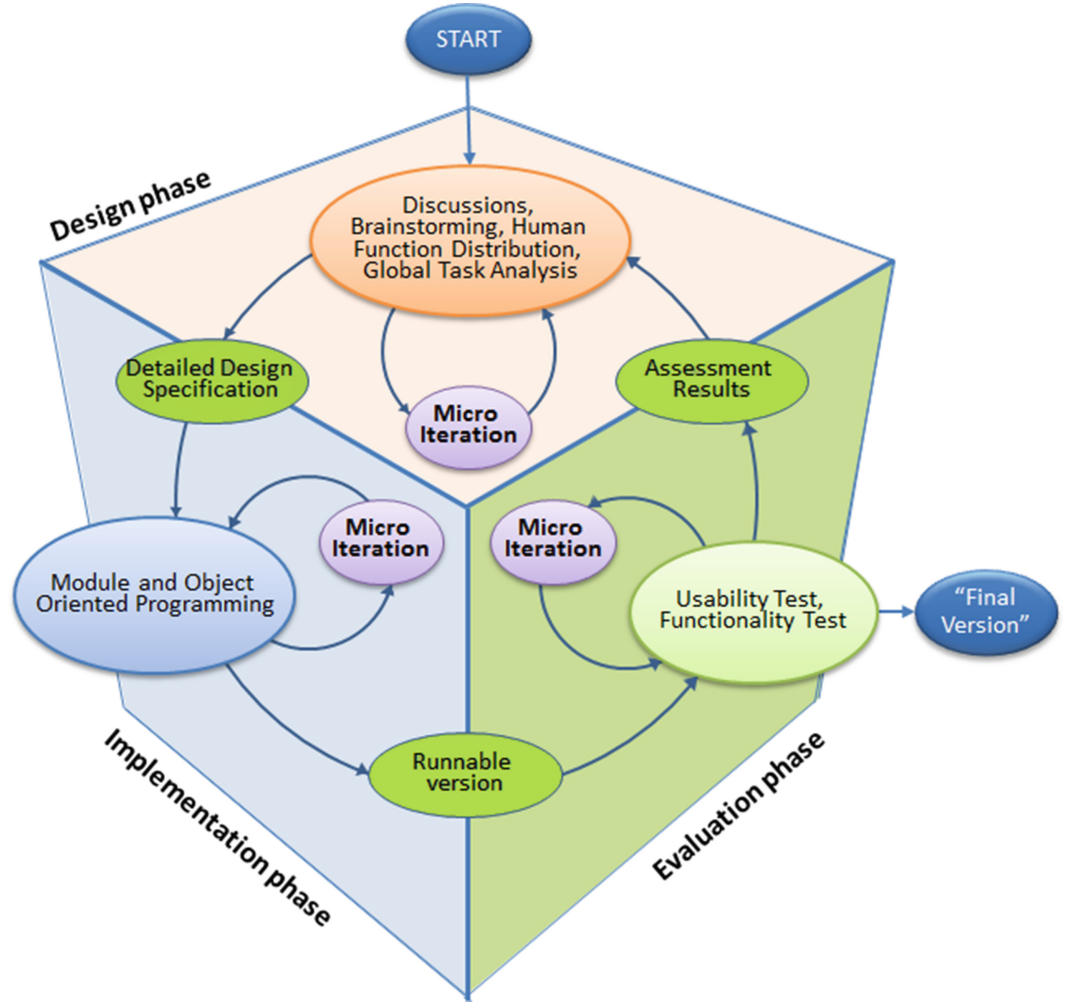

Fig. 1. Overview of the development process

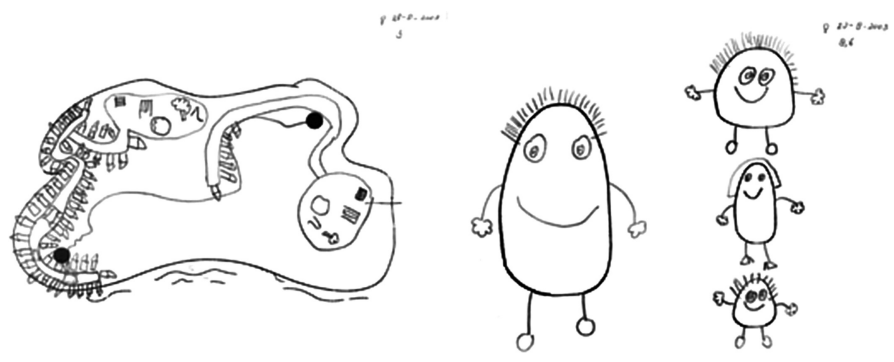

Fig. 2. Sample design of the game setting and characters by a child

internal validity benefits of using a game in the first place. To solve this problem, instead of first thinking about the whole concrete story of the game all at once, we used the theme of the game more as a loose framework. Then we designed each mini-game to serve a diagnostic purpose and tailored it into a single story line. This process needs sub-iterations to fine tune each mini-game to work with the other mini-games. To create a good story, the book by C.H Miller, 'Digital storytelling: a creator's guide to interactive entertainment' is found to be useful [19]. 
After the mini-games were designed, we needed to transfer the abstract ideas of mini-games to the team members. Visual communication was found to be more efficient than verbal communication [20]. We chose to present the game with a simple flow chart (see Fig. 3). This was not only better in explaining the flow of game to the team members, but also gave us an advantage when we were going to implement the abstract game with a game engine.

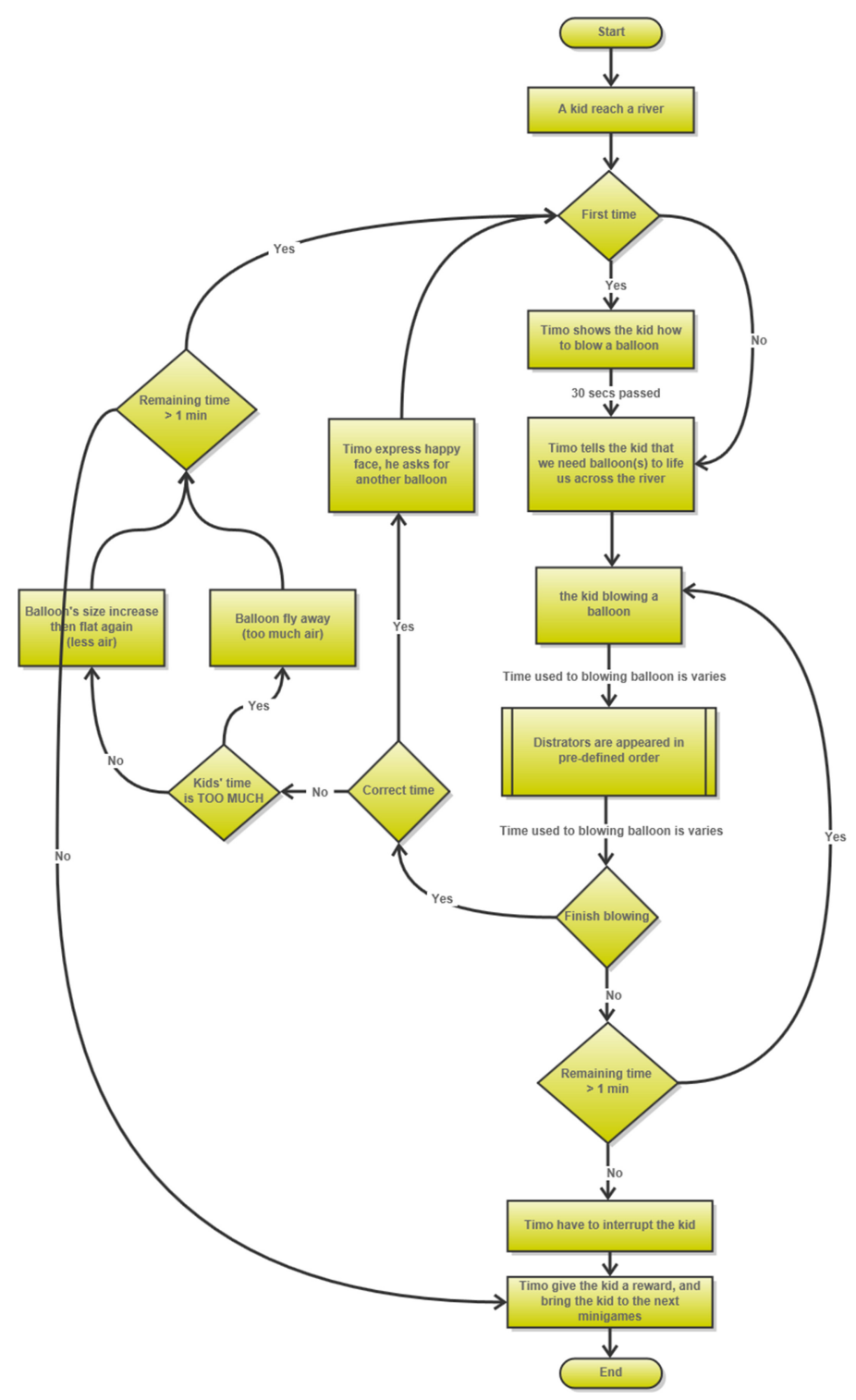

Fig. 3. Sample design of a mini-game called 'the balloon' 


\subsection{Implementation Phase}

The implementation phase focused on the implementation techniques of the game. We selected Unity ${ }^{1}$ for our game engine.. The game is written in $\mathrm{C \#}$ in MonoDeveloper; Unity's native integrated development environment (IDE). In fact, one can use three different languages: C\#, JavaScript, or Boo. We choose C\# because of its strict syntax. One may think that this makes coding harder, but we think that this help us with more robustness.

Concerning the reusability, each mini-game is broken down into a number of modules according to their functionality (see Fig. 4). The core module is the 'Gameplay Manager' that controls the flow of game play in each mini-game. Since each mini-game is unique it has its own 'Intro Manager' and 'Ending Manager', with which we can program an introduction and an ending respectively. There are common shared modules; 'Database Manager' to connect with a SQLite database file, 'Interaction Manager' to record user interaction, 'File Manager' to handle read/write log files, and 'Scene Transition Manager' to control the game's camera movement. The order of execution is shown in Fig. 4.

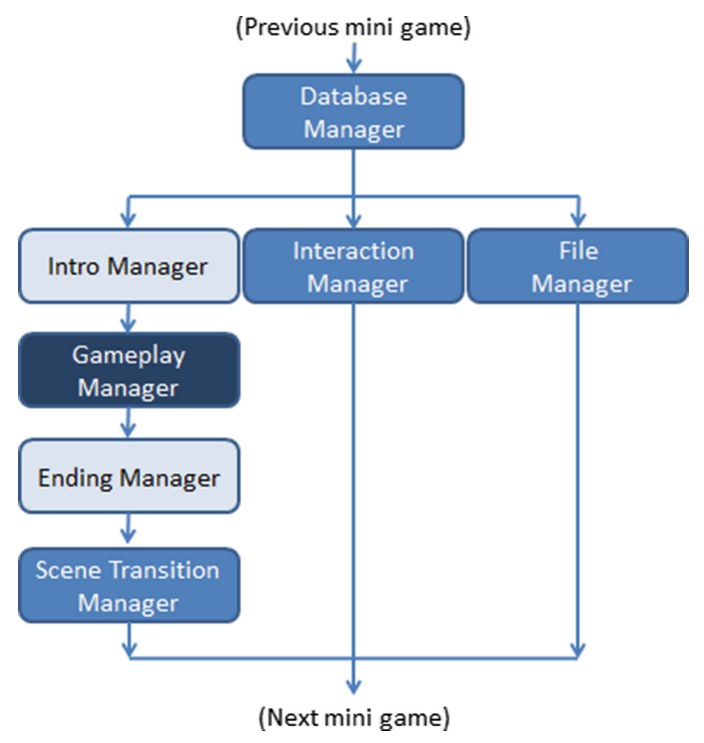

Fig. 4. Modules in each mini-game

1. 'Database Manager' has the responsibility to make a connection to a SQLite database file. It retrieves a dataset and puts this into an ArrayList in order to prepare the game variables before they can be accessed by the 'Gameplay Manager'.

\footnotetext{
${ }^{1}$ Unity3D Game Engine, http://unity3d.com/.
} 
2. The 'Intro Manager' is called to play an introduction, and since each mini-game is unique, it demonstrates how to play a mini-game before the children start playing the game.

3. Meanwhile an 'Interaction Manager' is prepared to gather all the clicking data and to send these to a 'File Manager' in the form of a chunk of strings, before being periodically written to a log file.

4. The 'Gameplay Manager' is executed after the introduction. The children play the game without knowing that they are being observed and their clicking data are being logged.

5. After the game is finished, the 'Ending manager' is called. A map of the overall game is shown so children know how many mini-games are left. This module plays the ending cinematics to ensure that children know that the current mini-game is over and that they should get ready for the next mini-game.

6. A 'Scene Transition Manager' is called at last, to bring children to the next mini-game in a first person perspective and two and a half dimensional game environment.

There were many 3D computer models in the game. All of them were made using Blender ${ }^{2}$, a polygonal mesh object modeling program. Unity and Blender can seamlessly work together. We can create a model in Blender and save it as a blend file and place it directly into the Unity game folder. Unity is smart enough to detect the file and import it into the game as an asset which we can select and use in the game. If any modification is needed, we just select the imported model and open it again in Blender, make the modification, then overwrite the old file. Unity will automatically re-import the model,. The process is very convenient and productive. Many tutorials about Blender on YouTube are available, but attention needs to be paid to the correct version, because Blender is open source, a different version has a slightly different user interface and this may cause some confusion.

The other requirement was that the game should be able to have its parameters modified without the need of a technical expertise. If we hard code parameters inside the game, we must re-compile the game every time when a modification is made. Therefore, our game is designed to read a property file when the game is launched. The property file is merely a text file with tab separated values. The game will configure the values with shared global variables, like a lookup table, where each mini-game can have access to. This process is done quickly while the game is launched with the title screen. Hard coding of default values is still needed in order to secure that the game can run even without the property file.

\subsection{Evaluation Phase}

In the evaluation phase, an approval from medical ethical committees is needed before conducting tests. It normally takes several months to get the approval. To get the feedback earlier, we asked children from our colleagues to volunteer instead. The

\footnotetext{
${ }^{2}$ Blender 3D Modeling tool, http://www.blender.org/.
} 
parents of the children were well informed about the game and gave us consent for the user test, as well as consent to video record the test. The recorded video was for the research purpose of the game development team only and won't be publicly published. Every volunteer was given a small incentive.

The characteristics of a participant were noted down with an anonymous user persona. For example, "Busko is in her first grade. She likes going to school, she has some nice friends and she likes that she finally learns to read. Mathematics, however, is more difficult for her, but with hard work she manages. Her favorite activity at school is drawing or gymnastics.

She lives at home with her mom and dad, and a 4 year old younger sister. In her free time she plays with her sister. Although she likes to play with her sister, they sometimes argue. It is no problem for her to keep herself busy. She has a lot of interests and can play for hours. She likes playing with Barbies, and taking stories with Barbies. Furthermore, Busko is a member of the local judo club. The parents are proud of the fact that she is self-reliant. She can make her own sandwich in the morning. They don't have any big concerns about Busko."

The test environment was set in a room with two desks, and a few chairs. The game was installed on a computer with a 23 inch LCD touch screen, being placed at $15 \mathrm{~cm}$ from the edge of the desk in front of the child. We put the keyboard away from the reach of the child. We covered any wall decorating pictures and book shelves with a white canvas to prevent them from being distracted while playing the game. The window blinds were put down, to prevent light from outside. There were only a psychologist and the child in the room. The parent(s) were not allowed inside, but waiting outside the room. The test started with a brief introduction by the psychologist. The child was informed that he/she is going to play a game, and was asked a few questions. The psychologist asked the child whether he/she wanted to go to a toilet before the game started. If everything was set, then the test begun. The test took around $30 \mathrm{~min}$.

The psychologist observed the child's behavior and took notes. It was deemed important to make sure that the child felt comfortable and did not feel lonely or anxious. However, the psychologist wasn't allowed in any way to help the child complete the game. If the child got stuck on something, the psychologist noted down a remark, because this could be valuable feedback for improvement in the next iteration. The behaviors of the child mco were video recorded, and the game itself logged the user interaction.

\subsection{Micro Iterations}

There were iterations at a level under the whole development cycle within each phase, adapted from 'an iterative-cyclic software process model' [21], so called 'micro iterations'. The purpose of a micro iteration is not solely a small iterative version of the containing phase, but focusing more on a collaborative process of synchronizing and scheduling. It is to optimize on time and human resources, make a concept clear, enable dynamic changes, and catch unwanted defects before they are passed on to the higher development phase. 
In the design phase, children were not the only users of the game, the participatory design model was also applied to psychologists who would use our game as a diagnostic tool. The participation included gathering requirements, implementing them, communicating and presenting them to the team members, getting their feedback and reconciling in open discussions. We modified the design according to the team feedback and comments. The aforementioned tasks were iterated until all team members agreed, before starting on the next phase.

In the implementation phase the programmer was encouraged to present a playable mini-game to the team, using rapid prototyping. The team was aware that the prototypes were not the final versions, so the micro iterations were not to find programming defects, but rather to present a proof of concept, and to discuss a solution in case that any limitation arose. The programmer could introduce additional elements that were not stated in the design, if they contributed to the design.

In the evaluation phase, we followed a user's perspective. The game must meet user requirements, and many times we found that we needed to make new improvements. For example, we added more game visual elements, smoothed the scene change, and improved the textures of game objects. Of course, this would bring us back to the design phase and implementation phase. But considering the completeness and usefulness of the game this also necessary. Every micro iteration was well documented for later reference in case of inconsistency and misunderstanding.

\section{Conclusion and Future Work}

In this paper, we present our experience in designing a diagnostic game. User requirements are presented to show what the final goal is, as well as the iteration phases. The iterative process can prevent problems from slipping though during the development. It helps incremental development of the game and allows changes during the development.

Design needs lots of creativity and time. And still this does not preclude the terrifying moment for a designer that at the end of the day the work can be rejected by the end user. In order to increase the level of acceptance from the user perspective, we followed the design process of participatory design and user-centred design. We have seen that the children who we invited to participate in our design really loved to express their thoughts.

We implemented the game in the Unity game engine, and modeled the $3 \mathrm{D}$ models in Blender. One can program in C\#, JavaScript, or Boo. C\# was our preferred programming language because of its stick syntax. When the game becomes huge, only one module to do all the tasks is not enough. We applied a divide-and-conquer strategy of dividing it into sub modules, depending on its functionality, and grouping modules that had similar functionalities later. This enabled the usability of those modules, and it was easier to add more functionality. Unity supports running modules in parallel as long as it has been enabled and it is attached to a GameObject. We control the order of execution, disabling others modules and enabling them when needed.

The ideas acquired from each phase must be shared by every team member with different expertise and backgrounds. Micro iterations may help in sharing thoughts and 
synchronizing the actions. We found that visual communication worked better than verbal communication.

At the time of writing, we are currently conducting a full scale experiment. From the evaluation feedback so far we consider that the process we followed worked well for its purpose.

Acknowledgement. This work was supported by the Erasmus Mundus Joint Doctorate in Interactive and Cognitive Environments (ICE), which is funded by the EACEA Agency of the European Commission under EMJD ICE FPA n 2010-0012. We are also very grateful for the collaboration with \{Dr. Jos Hendriksen, Prof. Dr. Hans Vles, Prof. Dr. Bert Aldenkamp, and Janneke Peijnenborgh MSc.\} from Kempenhaeghe, Center for Neurological Learning Disabilities, and Christian Sallustro from Eindhoven University of Technology. This work also is co-funded by the EU under the FP7, in the Games and Learning Alliance (GaLA) Network of Excellence, Grant Agreement nr. 258169.

\section{References}

1. Bioulac, S., Arfi, L., Bouvard, M.P.: Attention deficit/hyperactivity disorder and video games: a comparative study of hyperactive and control children. Eur. Psychiatry. 23, 134141 (2008)

2. Bellotti, F., Berta, R., De Gloria, A.: Designing effective serious games: opportunities and challenges for research. Int. J. Emerg. Technol. Learn. 5, 22-35 (2010)

3. McCarney, R., Warner, J., Iliffe, S., van Haselen, R., Griffin, M., Fisher, P.: The hawthorne effect: a randomised, controlled trial. BMC Med. Res. Methodol. 7, 30 (2007)

4. Chen, J.: Flow in games (and everything else). Commun. ACM 50, 31-34 (2007)

5. Shute, V.J., Ventura, M., Bauer, M., Zapata-Rivera, D.: Melding the power of serious games and embedded assessment to monitor and foster learning. Serious Games Mech. Eff. 2, 295321 (2009)

6. Fullerton, T.: Game Design Workshop: A Playcentric Approach to Creating Innovative Games. CRC Press, Boca Raton (2008)

7. New breakthrough in diagnosis of ADHD. http://sydney.edu.au/news/84.html?newsstoryid= 4501

8. Montini, L.: CogCubed Is Using Games to Help Diagnose ADHD. http://www.health2con. com/news/2013/04/16/cogcubed-is-using-games-to-diagnose-adhd/

9. Boehm, B.: A spiral model of software development and enhancement. Computer (Long. Beach. Calif). 21, 61-72 (1988)

10. Rauterberg, M., Strohm, O., Kirsch, C.: Benefits of user-oriented software development based on an iterative cyclic process model for simultaneous engineering. Int. J. Ind. Ergon. 16, 391-410 (1995)

11. Greenberg, B.S., Sherry, J., Lachlan, K., Lucas, K., Holmstrom, A.: Orientations to video games among gender and age groups. Simul. Gaming. 41, 238-259 (2010)

12. Read, J., Gregory, P., Macfarlane, S., Mcmanus, B., Gray, P.: An investigation of participatory design with children - informant, balanced and facilitated design. Interaction Design and Children, pp. 53-64 (2002)

13. Rauterberg, M.: User centered design : what, why, and when. In: Graefe, E. (ed.) tekom Jahrestagung, pp. 175-178. Gesellschaft fuer technische Kommunikation e.V, Wiesbaden, Germany (2003) 
14. Tsao, W.: Child's Own Studio. http://www.childsown.com/

15. Adey, M.: Make with Grace. http://makewithgrace.com/

16. Draw Your Toy. http://drawyourtoy.blogspot.it/

17. Trefry, G.: Casual Game Design: Designing Play for the Gamer in All of Us. CRC Press, Boca Raton (2010)

18. Salen, K., Zimmerman, E.: Rules of play : game design fundamentals. MIT Press, Cambridge (2003)

19. Miller, C.H.: Digital Storytelling: A Creator's Guide to Interactive Entertainment. Focal Press/Elsevier, Burlington (2008)

20. Larkin, J., Simon, H.: Why a diagram is (sometimes) worth ten thousand words. Cogn. Sci. 99, 65-99 (1987)

21. Rauterberg, M.: An iterative-cyclic software process model. In: Proceedings of the Fourth International Conference on Software Engineering and Knowledge Engineering, pp. 600607 (1992) 


\section{Alessandro De Gloria (Ed.)}

\section{Games and Learning Alliance}

Third International Conference, GALA 2014 Bucharest, Romania, July 2-4, 2014 Revised Selected Papers

Springer 


\section{Lecture Notes in Computer Science}

Commenced Publication in 1973

Founding and Former Series Editors:

Gerhard Goos, Juris Hartmanis, and Jan van Leeuwen

\section{Editorial Board}

David Hutchison

Lancaster University, Lancaster, UK

Takeo Kanade

Carnegie Mellon University, Pittsburgh, PA, USA

Josef Kittler

University of Surrey, Guildford, UK

Jon M. Kleinberg

Cornell University, Ithaca, NY, USA

Friedemann Mattern

ETH Zurich, Zürich, Switzerland

John C. Mitchell

Stanford University, Stanford, CA, USA

Moni Naor

Weizmann Institute of Science, Rehovot, Israel

C. Pandu Rangan

Indian Institute of Technology, Madras, India

Bernhard Steffen

TU Dortmund University, Dortmund, Germany

Demetri Terzopoulos

University of California, Los Angeles, CA, USA

Doug Tygar

University of California, Berkeley, CA, USA

Gerhard Weikum

Max Planck Institute for Informatics, Saarbrücken, Germany 
More information about this series at http://www.springer.com/series/7409 
Alessandro De Gloria (Ed.)

\section{Games and \\ Learning Alliance}

Third International Conference, GALA 2014 Bucharest, Romania, July 2-4, 2014 Revised Selected Papers 
Editor

Alessandro De Gloria

Electronic Engineering

University of Genova

Genova

Italy

ISSN 0302-9743

ISSN 1611-3349 (electronic)

Lecture Notes in Computer Science

ISBN 978-3-319-22959-1

ISBN 978-3-319-22960-7 (eBook)

DOI 10.1007/978-3-319-22960-7

Library of Congress Control Number: 2015948154

LNCS Sublibrary: SL3 - Information Systems and Applications, incl. Internet/Web, and HCI

Springer Cham Heidelberg New York Dordrecht London

(C) Springer International Publishing Switzerland 2015

This work is subject to copyright. All rights are reserved by the Publisher, whether the whole or part of the material is concerned, specifically the rights of translation, reprinting, reuse of illustrations, recitation, broadcasting, reproduction on microfilms or in any other physical way, and transmission or information storage and retrieval, electronic adaptation, computer software, or by similar or dissimilar methodology now known or hereafter developed.

The use of general descriptive names, registered names, trademarks, service marks, etc. in this publication does not imply, even in the absence of a specific statement, that such names are exempt from the relevant protective laws and regulations and therefore free for general use.

The publisher, the authors and the editors are safe to assume that the advice and information in this book are believed to be true and accurate at the date of publication. Neither the publisher nor the authors or the editors give a warranty, express or implied, with respect to the material contained herein or for any errors or omissions that may have been made.

Printed on acid-free paper

Springer International Publishing AG Switzerland is part of Springer Science+Business Media (www.springer.com) 


\section{Preface}

The third edition of the GALA Conference was held on July 2-4, 2014 in Bucharest, Romania. The conference was organized by the Serious Games Society and the Games and Learning Alliance, the European Network of Excellence on Serious Games (SGs).

The conference provided the opportunity for gathering and nurturing a community of experts on SGs, a community which is growing year by year and involves academics, industrial developers, teachers, and corporate decision makers, to promote knowledge sharing, technology transfer, and business development. This year, we also welcomed the participation of indie developers, which we believe represented a great opportunity and potential for improving and extending the technologies and applications of SGs.

As in previous years, the research presented covered a variety of aspects and knowledge fields. These have been grouped into four sessions: pedagogy, technology, design, and applications. The pedagogy session hosted studies about deployment of SGs at different school levels and on different topics. This constituted a significant advancement with respect to previous years, as it demonstrated that SGs have started to be used and deployed in authentic educational settings. One paper specifically investigates the role of the teacher in this new context.

The design and implementation session covered various aspects ranging from mobile games to multiplayer games, from formats to gamification of co-design processes and models for scaffolding game-based learning experiences.

The technology session included some very interesting papers about applying the Service Oriented Architecture paradigm to the field of SGs and multimodal emotion recognition in SGs.

Finally, the new games session presented some very interesting educational games, for instance in the field of physics, for training working memory, and for using social networks. Attention was paid in particular to special users, such as children with depression. Some papers presented interesting information on SG mechanics, which are at the core of SG design. Among them, we cite particularly virtual tutors and minigames.

This book collects the studies presented during the conference, addressing the above mentioned topics, with authors from a variety of countries and bringing knowledge from several different fields. Not only does this highlight the growing interest in SG applications in various domains, but also the multidisciplinary collaboration that is typically involved in SG design and deployment.

It is important to highlight that the papers presented at the Gala 2014 conference closely reflect this year's trend in research on serious games. In particular, we underline topics such as SG design research, rapid development frameworks, learning analytics, analysis of deployment in educational settings, brain-computer interaction, and applications in the health domain. Collaboration is targeted as well, and games are also cited as an appropriate tool within learning networks, the emerging paradigm through which 
more-experienced people help less-experienced people learn new skills and form new networks and communities. Mobile games and supporting technologies are also focused upon.

Like for the 2013 edition, the selected best papers of GALA 2014 will be published in a dedicated special issue of the International Journal of Serious Games, which represents a great opportunity for the scientific/technological community and for the industrial world as well to publish original research works on SGs and to be informed about the latest developments in the field. This year, the GALA 2012 best papers were published in an Entertainment Computing special issue.

July 2015

Alessandro De Gloria 


\section{Organization}

GALA 2014 was an event organized by Carol I National Defence University and the University of Genoa, and sponsored by the Games and Learning Alliance (GaLA) European Network of Excellence and by the Serious Games Society. The organizational structure was as follows:

\section{General Chair}

Alessandro De Gloria University of Genoa, Italy

\section{General Co-chair}

Ion Roceanu

Carol I National Defence University, Romania

\section{Workshop and Tutorial Chair}

David Wortley UK

\section{Program Committee}

Aida Azadegan

Albert Angehrn

Alessandro Berni

Ana Paiva

Andreas Oikonomou

Anthony Brooks

Audrius Jurgelionis

Baltasar

Fernandez-Manjon

Bianca Falcidieno

Brian Goldiez

Carmen Padron

Carolina Islas Sedano

Christos Gatzidis

Damien Djaouti

Daniel Burgos

David Wortley

Dirk Ifenthaler

Donald Brinkman

Erik Duval

Erik van der Spek

Fabrizia Mantovani

Francesco Bellotti
The University of West Scotland, UK

INSEAD, France

NATO, Italy

INESC-ID, Portugal

University of Derby, UK

Aalborg University, Denmark

Fraunhofer, Germany

Complutense University Madrid, Spain

CNR IMATI, Italy

University of Central Florida, USA

ATOS, Spain

University of Eastern Finland, Finland

Bournemouth University, UK

IRIT, France

UNIR, Spain

UK

Open Universities Australia, Australia

Microsoft, USA

Catholic University Leuven, Belgium

Technical University of Eindhoven, The Netherlands

Università di Milano-Bicocca, Italy

University of Genoa, Italy 
Francisco José Gallego Durán

George Lepouras

Frank Dignum

Igor Mayer

Ioana Stanescu

Ion Roceanu

Ivan Lombardi

J.C. Hertz

Jannicke M.

Baalsrud Hauge

Johann Riedel

Josef Froschauer

Kam Star

Katerina Mania

Kristian Kiili

Kurt Debattista

Kyung-Sik Kim

Leonardo Caporarello

Lucia Pannese

Marcello Carrozzino

Margarida Romero

Maria Magdalena Popescu

Marius Preda

Mark McMahon

Matthias Rauterberg

Michael Derntl

Michael Kickmeier-Rust

Michela Mortara

Miguel Encarnação

Milos Kravcik

Muriel Ney

Nahum D. Gershon

Nathalie Charlier

Norman Badler

Ole-Ivar Holthe

Olivier Irrmann

Pablo Moreno-Ger

Panagiotis Petridis

Paolo Riva

Per Backlund

Peter Van Rosmalen

Rafael Bidarra

Ralph Klamma

Riccardo Berta
University of Alicante, Spain

University of the Peloponnese, Greece

University of Utrecht, Netherlands

Technical University of Delft, Netherlands

Carol I Nat. Defence University, Romania

Carol I Nat. Defence University, Romania

Catholic University Sacred Heart, Milan, Italy

USA

Bremer Institut für Produktion und Logistik GmbH, Germany

University of Nottingham, UK

Vienna University of Technology, Austria

Playgen, UK

Technical University of Crete, Greece

Tampere University of Technology, Finland

Univeristy of Warwick, UK

Dankook University, South Korea

SDA Bocconi School of Management, Italy

imaginary, Italy

Institute for Advanced Studies Lucca, Italy

Esade, Spain

Carol I Nat. Defence University, Romania

Institut National des Télécommunications, France

Edith Cowan University, Australia

Technical University of Eindhoven, Netherlands

RWTH Aachen, Germany

Technical University of Graz, Austria

CNR, Italy

University of Louisville, USA

RWTH Aachen, Germany

Imag, France

MITRE, USA

Katholieke Universiteit Leuven, Belgium

University of Pennsylvania, USA

Geelix, Norway

Aalto University, Finland

Complutense University Madrid, Spain

Serious Games Institute, UK

Università di Milano-Bicocca, Italy

Högskolan i Skövde, Sweden

Open University of the Netherlands, Netherlands

Delft University of Technology, Netherlands

RWTH Aachen, Germany

University of Genoa, Italy 
Rob Nadolsky

Rosa Maria Bottino

Rui Prada

Sandy Louchart

Sara de Freitas

Simon

Egenfeldt-Nielsen

Staffan Bjork

Stephen Lane

Steve Ellis

Sung Hyun Cho

Tanya Krzywinska

Theo Lim

Travis Ross

William Fisher

Wim Westera

Yiorgos Chrysanthou
Open University, Netherlands

National Research Institute, Italy

Inesc-Id, Portugal

Heriot-Watt University, UK

Coventry University, UK

Serious Games Interactive, Denmark)

Chalmers Unibersity, Sweden

University of Pennsylvania, USA

NASA, USA

Hongik University, South Korea

Brunel University, UK

Heriot-Watt University, UK

Indiana University, USA

Quicksilver, USA

Open University of the Netherlands, Netherlands

University of Cyprus, Cyprus

\section{Local Arrangements Committee}

Daniel Beligan

Elisa Lavagnino
Carol I National Defence University, Romania

University of Genoa, Italy

\section{Publications Chair}

Riccardo Berta

University of Genoa, Italy

\section{Communication Chair}

Francesco Bellotti University of Genoa, Italy

\section{Administrative Chair}

Elisa Lavagnino

University of Genoa, Italy

Antonie Wiedemann

University of Genoa, Italy 


\section{Contents}

Beyond Serious Games: The Next Generation of Cultural Artifacts . . . . . . . 1 Federico Fasce

Investigating the Deployment of Serious Games in Secondary Education:

A Pilot Study Inspired by Design-Based Research. . . . . . . . . . . . . . .

Jeffrey Earp, Chiara Eva Catalano, and Michela Mortara

To Facilitate or Not? Understanding the Role of the Teacher in Using

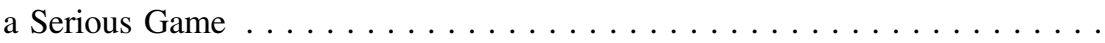

Jannicke Baalsrud Hauge, Theodore Lim, James Ritchie,

Matthias Kalverkamp, Francesco Bellotti, and Claudia Ribeiro

Identifying Pedagogical Uses of Serious Games for Learning English

as a Second Language . . . . . . . . . . . . . . . . . . .

Azeneth Patiño and Margarida Romero

Intouch: Mobile Game-Based Learning for Non Routine Skills . . . . . . . . . . .

Alfredo Imbellone, Brunella Botte, and Carlo Maria Medaglia

Multiplayer Serious Games and User Experience: A Comparison Between

Paper-Based and Digital Gaming Experience . . . . . . . . . . . . . . .

Luca Argenton, Marisa Muzio, Esther J. Shek, and Fabrizia Mantovani

Designing a Serious Game as a Diagnostic Tool . . . . . . . . . . . . . .

Pongpanote Gongsook, Janneke Peijnenborgh, Erik van der Spek,

Jun Hu, Francesco Bellotti, Riccardo Berta, Alessandro de Gloria,

Francesco Curatelli, Chiara Martinengo, Matthias Rauterberg,

and Jos Hendriksen

Gamification in a Smart City Context. An Analysis and a Proposal for Its

Application in Co-design Processes . . . . . . . . . . . . . . . . .

Antonio Opromolla, Andrea Ingrosso, Valentina Volpi,

Carlo Maria Medaglia, Mauro Palatucci, and Mariarosaria Pazzola

A Conceptual Model Towards the Scaffolding of Learning Experience . . . . . Sylvester Arnab, Pablo Moreno Ger, Theodore Lim, Petros Lameras, Maurice Hendrix, Kristian Kiili, Jannicke Baalsrud Hauge, Manuel Ninaus, Sara de Freitas, Alessandro Mazzetti, Anders Dahlbom, Cristiana Degano, Ioana Stanescu, and Maria Riveiro 
The Journey: A Service-Based Adaptive Serious Game on Probability. . . . . .

Maira B. Carvalho, Francesco Bellotti, Riccardo Berta,

Francesco Curatelli, Alessandro De Gloria, Giorgia Gazzarata, Jun Hu,

Michael Kickmeier-Rust, and Chiara Martinengo

Improved Multimodal Emotion Recognition for Better Game-Based

Learning . . . . . . . . . . . . . . . . . . . . . . . . . .

Kiavash Bahreini, Rob Nadolski, and Wim Westera

Serious Games Opportunities for the Primary Education Curriculum

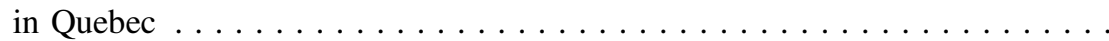

Margarida Romero and Sylvie Barma

Free Your Brain a Working Memory Training Game. . . . . . . . . . . . . . .

Gonçalo Pereira, Manuel Ninaus, Rui Prada, Guilherme Wood,

Christa Neuper, and Ana Paiva

Game Design and Development for Learning Physics Using the Flow

Framework. . . . . . . . . . . . . . . . . . . . . . . . . . .

Danu Pranantha, Erik van der Spek, Francesco Bellotti, Riccardo Berta, Alessandro De Gloria, and Matthias Rauterberg

Mind Book - A Social Network Trainer for Children with Depression. . . . . . Andreas Schrammel, Helmut Hlavacs, Manuel Sprung, Isabelle Müller, M. Mersits, C. Eicher, and N. Schmitz.

Using Avatars for Course Management and Immersion . . . . . . . . . . . Martin Sillaots

Serious Game Mechanics, Workshop on the Ludo-Pedagogical

Mechanism.

T. Lim, S. Louchart, N. Suttie, J. Baalsrud Hauge, J. Earp, M. Ott,

S. Arnab, D. Brown, I.A. Stanescu, F. Bellotti, and M. Carvalho 